\title{
Delimiting Dimensions and Indicators in Students' Research Papers on EFL Education: A Cuban Perspective
}

\author{
Juan Carlos Vega Puente, Jorge Carlos Ronda Pupo, Yakeline Herrera Fuentes \\ Department of English and French Languages, Faculty of Education in Foreign Languages, Enrique José Varona University of Pedagogical \\ Sciences, Havana, Cuba \\ Email address: \\ juankavp58@gmail.com (J. C. V. Puente),jorgecrp@ucpejv.edu.cu (J. C. R. Pupo), yakelinehf@ucpejv.edu.cu (Y. H. Fuentes)

\section{To cite this article:} \\ Juan Carlos Vega Puente, Jorge Carlos Ronda Pupo, Yakeline Herrera Fuentes. Delimiting Dimensions and Indicators in Students' Research \\ Papers on EFL Education: A Cuban Perspective. Science Journal of Education. Vol. 9, No. 4, 2021, pp. 131-142. \\ doi: $10.11648 /$ j.sjedu.20210904.12
}

Received: July 7, 2021; Accepted: July 19, 2021; Published: August 31, 2021

\begin{abstract}
The development of scientific research skills has always been an aim in the formation of English as a foreign language (EFL) teaching professionals. In this respect, the determination of dimensions and indicators, with emphasis on the latter, has become a key step in the process of research. This work aims at providing students-researchers and advisors with the conceptualization of essential categories, some recommendations and examples of dimensions and indicators derived from the authors' professional experience, the review of specialized bibliography on the topic and the analysis of the inventory of diploma papers (pieces of research presented as a requirement to complete undergraduate programs of study) and Master's degree theses from Enrique José Varona University of Pedagogical Sciences and the University of Havana. The dimensions and indicators discussed cover two basic areas in EFL education research, namely levels of discourse construction (pronunciation, vocabulary, grammar, discourse and text studies) and types of verbal activity (speaking, writing, listening and reading). The article responds to a task from the research project: The enhancement of English teaching in Primary, High and Higher Educations, carried out at the Faculty of Education in Foreign Languages from Enrique José Varona University of Pedagogical Sciences, which is part of the National Program: The Cuban Educational System: perspective of development.
\end{abstract}

Keywords: Research, Independent Variable, Dependent Variable, Dimensions, Indicators

\section{Introduction}

When the students, either undergraduates or graduates, start working on their research papers, it is quite difficult for them to determine the dimensions and indicators of the dependent variable, which they should use throughout the study. Undoubtedly, their definition plays a key role in devising the instruments of the different methods of both quantitative and qualitative inquiry employed along the whole process, particularly during the diagnosis of the initial state of the problem, when designing its solution (independent variable) and assessing the outcomes of the study.

The objective of this work is to share Cuban experiences of equipping students engaged in EFL education research and their scientific advisors with key concepts and recommendations on how to define dimensions and indicators, as well as with some examples of dimensions and indicators relevant for the study of two topics frequently tackled in the abovementioned domain of social activity: levels of discourse construction and types of verbal activity.

\section{Basic Assumptions About Variables, Dimensions and Indicators of the Research Papers in EFL Education}

It is common knowledge that there are two main variables or factors commonly distinguished in scientific research - the dependent and the independent ones. According to Vega and Chala, in foreign language education research, the dependent variable is the challenging aspect within the pedagogical process causing some troubles and hindering the successful attainment of the objectives in a given educational context. Thus, it becomes the object of the research, i.e. the target at which actions and thoughts are directed in order to improve 
the teaching-learning process in that setting. For instance, listening learning strategies make up the dependent variable in the thesis Methodology to develop listening learning strategies in Integrated English Practice I and II. The object is expected to change under the influence of a new idea or approach to the EFL teaching and learning. This solution the researcher introduces so as to transform the object for the better, to cope with the difficulties detected in the referred process, is termed independent variable, e.g. the methodology devised in the paper mentioned earlier $[1,2]$.

Since the object or dependent variable of the research is what needs to be changed in the context investigated, the student-researcher should have a model interpretation of the target language content in order to determine the direction of the transformations to be produced. This concept of the object, as Walliman and Baiche [3] point out, includes its main constituents and features, known as dimensions and indicators. Dimensions, or invariants, are essential aspects or component parts within the concept of the research objects, related to English language, its use to communicate and EFL didactics. Indicators, or parameters, are the ways dimensions are manifested; the salient features or pointers that make them noticeable and measurable. Therefore, researchers use indicators to study how a dimension is evident, to assess the degree to which it is expressed.

Accordingly, it is necessary to operationalize the dependent variable, which implies to break down the object into dimensions and indicators, and to describe them as the relevant points of reference that allow accomplishing the investigation. The precise definition of these categories has special significance for the diagnosis of positive and negative aspects during the characterization of the linguodidactic problem in the context explored, the design of the solution to cope with it, and the assessment of the modification produced in the object by the solution devised.

Delimiting dimensions and indicators is really hard work. Actually, it represents one of the greatest challenges in the research process. Once the object has been identified, it is indispensable for the student to reflect on his/her own language teaching experiences, to revise the literature on the topic, and to consult specialists and practiced educators. However, this is not an easy process at all. Linguists and experts in language education explain the concepts of the object studied in different ways and make use of diverse terms to name its features. Thus, Medina, Tejeda, Quevedo, Cruz and Limonta [4] emphasize the importance of training students-researchers in how to evaluate the sources critically, and to systematize them in accordance with the foundations adopted.

Likewise, it is of great consequence to make students aware of the fact that the decision on this issue is generally based on two procedures: choosing the dimensions and indicators a given author has delimited or integrating and adapting the ideas of several authors that share the same theoretical foundations (the communicative approach in language teaching or discourse linguistics in language studies, for instance). The former is applicable when the conception of the author chosen is completely suitable for the paper purpose and the context explored. The latter becomes necessary if none of the authors consulted covers all the aspects of the object tackled in the setting studied, especially when the researcher resolves to integrate the theoretical bases discussed into a working definition, which as a rule contains the specific characteristics of the object conceptualized.

Whatever the procedure used is, in the paper the young researcher should unfold this theoretical search through the sources, the evaluation of different approaches and the reasons for the positions the author decides to take. This process leads to the definition of the dependent variable, its dimensions and indicators, which need to be precisely expressed in consonance with the semantic, formal, functional aspects of the linguistic content investigated, and with contextual factors concerned with its teaching and learning, such as curriculum requirements and learner's cognitive and linguistic development.

Among the contextual factors pondered, the definition and treatment of dimensions and indicators includes the consideration of students' mother tongue and cultural identity, which may be accomplished through the explicit or the implicit comparative perspective. The understanding of these procedures develops from the conceptual framework offered by Bermello and González $[5,6]$. The explicit perspective deals with the open reference to similarities and differences between English and Spanish concerning the object. The implicit one consists in making emphasis on a distinctive feature of English without pointing out to the difference with Spanish openly.

Valledor, Ceballo, Blanco and Ferrás [7] consider that in undergraduate papers it is enough to determine the indicators. However, pointing out both dimensions and indicators would help the author have a clearer perspective of what to change, and how to organize the description of the facts resulting from the study in a more appropriate manner. Let's say the development of listening learning strategies in the thesis mentioned before covers three dimensions with their respective indicators: cognitive strategies (awareness of the strategies, use of the strategies to decode oral messages and use of the strategies to interpret oral messages in context), metacognitive strategies (procedures to plan the use of the strategies, procedures to regulate the application of the strategies and procedures to assess the results of the strategies) and socio-affective strategies (procedures to express listener's attitudes and procedures to infer speaker's motivation, attitude or mood).

If the student decides to use only indicators, they must be tangible, assessable expressions of the dependent variable. In the examination of the undergraduate papers two effective approaches to do this were identified:

a. Delimiting just the concrete features to be evaluated with its explanation, e.g. in a research work dealing with the object illustrated before, the author may follow just the seven indicators mentioned.

b. Treating the component areas of the object as indicators. This approach entails a comprehensive 
explanation of each area containing the characteristics serving to indicate its expression. For instance, if the author uses as indicators the dimensional areas referred to above, their definitions would include the specific markers of its manifestation, otherwise considered the indicators of each kind of strategy.

In Master theses, because of the depth these studies presuppose, the dimensions and their indicators are indispensable.

Regarding the formulation of dimensions and indicators, the analysis of the papers has disclosed three major procedures. The first one consists in representing the conceptual components and their indicative signs with the corresponding terms, as just exemplified above with the types of listening learning strategies and their concrete realizations. In the second, these categories are stated as skills, understood in this article as the proficient use of specific discourse actions with a certain purpose in the contextual exchange of meanings. This concept has become a central category in EFL communicative teaching for they are guided by intentions and context-based functioning. The skill-oriented presentation actually correlates with the parallel terms, e.g. the dimension 'metacognitive strategy' may be expressed as 'employing a metacognitive strategy'; its indicators as 'planning its use', 'regulating its application' and 'assessing its results'. The third procedure combines the preceding ones; mostly dimensions are formulated by means of terms and indicators, as skills.

In general, it is up to the student-researcher, primarily, and the advisor, as mentor, to determine the dimensions and/or indicators required in the study, which essentially depends on the specific topic, the objective and the context of the research, and to formulate them accordingly. The critical point is to conceive them as an effective system supporting the research process.

\section{Methods Employed in the Study}

The ideas discussed in the article mainly stem from the bibliographic review, the analysis of graduate and undergraduate students' research papers, as well as authors' professional experience.

The bibliographic review covers sources on English applied linguistics; English as foreign language didactics and educational research, with emphasis on those produced in the Cuban context, for the article reflects standpoints prevailing in it. The criteria employed for the content analysis of the bibliography include: the concepts of variable, dimension and indicator, the definition of these categories with reference to the levels of discourse construction and types of verbal activity, the suitability of these concepts and definitions for the purpose of this study, particularly for the explanations offered in the article, as well as the use of comparison in their research.

The study comprises research works concerning levels of discourse construction and types of verbal activity, as well as eight fields within them. The papers included are those presented from 2010 to 2020 at Enrique José Varona University of Pedagogical Sciences and the University of Havana, the two Havana's institutions of higher education in which the formation EFL teaching professionals takes place. The analysis includes 47 diploma papers and 15 Master's degree theses. Out of them, 23 diploma papers, selected through a proportional stratified random sampling procedure so as to represent each of the eight fields examined, and eight theses. The whole target population belongs to authors from Enrique José Varona University of Pedagogical Sciences. In addition, the analysis involves 15 diploma papers and 27 theses from the University of Havana, the ones available to the authors of the article.

The qualitative assessment of these areas has helped to evaluate how dimensions and indicators are deduced from the areas in each of the eight fields studied, as well as to explain the process of delimiting these categories. The criteria followed for the assessment, the first two adapted from Perry [9], are: accuracy, pertinence to the object under investigation and the contribution of the dimensions and indicators to the achievement of the objective, content coverage, consideration of relevant semantic, formal, functional and sociocultural aspects, their contextualization and treatment from the explicit or implicit comparative perspective, and presentation, definition of dimensions and/or indicators, as well as their formulation by means of terms or skills.

The quantitative analysis has complemented the qualitative evaluation of these areas Mode has been used for the quantitative analysis of the data to estimate the most frequent areas serving to determine the dimensions or indicators in each field, and the mistakes in determining them within each of the two global topics examined. The areas and mistakes considered are those having the three highest frequency scores. Mean has helped to establish the average presentation of dimensions and indicators with terms or skills, the average use of the explicit or the implicit comparative perspectives in their treatment, and the percentile of papers with inaccurate delimitation of one or more dimensions or indicators. The full description of the methods, procedures and data gathered is offered in the task research report for the project [8].

The analysis of undergraduate students' research papers, carried out by Ronda and Herrera, and of Master's degree theses, accomplished by Vega, has allowed the authors to identify strengths and weaknesses as to the definition of dimensions and indicators, and to illustrate the process of deciding upon them.

\section{The Fields in EFL Education Research Selected: The Delimitation of Dimensions and Indicators in Them}

This is by no means a complete account of the topics in EFL education research or of the dimensions and the indicators followed in these studies. As stated before, the 
article restricts itself to two issues containing eight fields, within which a varied spectrum of specific categories may be contextually relevant. Another significant point to make is that any of the fields discussed can be set as the dependent variable, which demands that the researcher singles out the dimensions and/or the indicators out of the areas associated to the given topic. It is also possible to center the study on one of the areas within the field or one of the components within this area.

\subsection{Levels of Discourse Construction}

The levels of discourse construction may be understood as the structural layers of language means and relations sharing semantic, formal and functional properties (phonological, lexical, grammatical and textual) that provide a given tongue with a systemic arrangement, that make it an organic whole of coherently organized units and relationships. This notion becomes a significant tool in the teaching-learning process of linguistic contents as the exponents of diverse communicative functions.

Among the papers dealing with these levels, the $47.8 \%$ shows difficulties with the accuracy of dimensions and the indicators. The most frequent inaccuracies may be summarized as follows:

1. These categories are not delimited.

2. The use of one or more of the categories without discussing their theoretical bases, e.g. treating motivation as an indicator without reference to how it is fostered.

3. The delimitation of categories concerning the independent variable instead of the object, e.g. a paper on the teaching aids for the learning of vocabulary determines the dimensions and indicators in terms of the selection, design and use of the aids and not of the aspects in vocabulary learning developed under their influence.

4. The indeterminate or inconsistent consideration the categories defined in the components of the solution (activities, tasks, analyses, methodology or web page, etc.).

A common aspect in relation to the content coverage is the prevailing use of the implicit comparison. The flaws in this respect are spotlighted at the end of the review of each field. As to the presentation of dimensions and indicators, the research works devoted to discourse construction levels predominantly represent them by using terms, though it is easy to connect them to the related skills, as evident in the subsequent analyses. A recurrent difficulty regarding their presentation consists in a too general or imprecise definition of a category making it impractical to assess to what degree it is present.

\subsubsection{Pronunciation}

The chart below shows the areas concerning pronunciation, its teaching and learning that are more frequently used to determine the dimensions and the indicators. The explanation of the areas and features considered in the article derives from the conceptions of Correoso and García (2012), and Rodríguez (2018) [10, 11].
Table 1. Frequent areas tackled in the field of pronunciation.

\begin{tabular}{ll}
\hline Field & $\begin{array}{l}\text { Areas in the field helping to delimit dimensions and } \\
\text { indicators }\end{array}$ \\
\hline \multirow{3}{*}{ Pronunciation } & $\begin{array}{l}\text { 1. Articulation of sounds } \\
\text { 2. Intonation } \\
\text { 3. Rhythm } \\
\text { 4. Stress }\end{array}$ \\
\hline
\end{tabular}

As stated before, if pronunciation as a whole is the object of the research, the author must decide whether it is necessary to cover all or some of the areas pointed out as dimensions, and then determine the indicators appropriate to assess the dimensions chosen. Since pronunciation areas cover a wide range of problems, authors often focus on some specific issues affecting the teaching-learning process in the educational institutions where they work. In general, the content coverage and the emphasis on one or another aspect are justified by the curricular requirements and students' needs.

The thesis Developing English pronunciation skills in the subject Phonetics and Phonology for third year students at the Faculty of Foreign Languages [12], comprises the four areas as dimensions and a comprehensive description of their indicators for it tackles English teacher training. For this reason, the paper adds other two dimensions: phonetic changes in connected speech and corrective phonetics. The latter frequently forms part of the solution, of the independent variable, in papers intended for other students. All over the work the explicit comparison is emphasized through the phonological opposition.

A narrower scope is covered in the undergraduate paper $A$ web page to enhance the pronunciation English vowels in $10^{\text {th }}$ graders, in which the examination of the object is based on the classification of vowels into monophthongs and diphthongs as dimensions. In the function of indicators of monophthongs, the author takes into account the principles used for their description: the position of the soft palate, the position of the tongue (horizontal movement of the tongue), the height of the raised part of the tongue (vertical movement), the lip position, the position of the lower jaw, the degree of tenseness, the length of the vowel. As indicators of diphthongs, function: the direction of the movement, the change of stress, the length of the glide, and the movement of the jaw. This full account of types and characteristics of consonant pronunciation is not required in a piece of work coping with difficulties in the articulation of specific English sounds. Hence, the paper Activities and corrective techniques to improve 9th graders' pronunciation of consonant sounds $/ \mathrm{d} /, / \theta /, / v /$ and $/ b /$, the pronunciation of these consonant sounds is the dependent variable. Just indicators are determined, and this is one of the few cases within the field that formulates them in terms of skills: accurately producing the consonants according to place of articulation, the manner of articulation, the work of the vocal cords and force of articulation. The fifth principle used for consonant articulation, position of the soft palate, is disregarded since the four sounds are oral $[13,14]$.

A different and interesting outcome is offered in another thesis entitled System of communicative exercises to develop 
habits of using stress patterns in English words with cognates in Spanish in secondary students from the International School of Havana [15], based on the following dimensions and indicators: similarities and differences of the stress patterns (dimensions) as to the position of the stress syllable, the phonic structure of the stress syllable, the word class of the cognates and the amount of syllables (indicators).

A paper tackling another of the areas in the chart, entitled Set of activities for the teaching of English intonation to 10th grade students [16], considers only indicators of the dependent variable: stress, rhythm and pitch prominence, with the help of which the explanation, practice and evaluation of the use of intonation patterns is carried out.

It seems important to notice that there are three basic concept areas scarcely addressed in research papers: phonetic changes in connected speech, learning strategies and motivation for improving pronunciation, despite the significant impact of the first on the functional-stylistic shape of speech performance, and of the last two on Spanishspeakers' learning of English pronunciation.

\subsubsection{Vocabulary}

According to the review of students' papers concerning vocabulary, its teaching and learning, the areas are those listed in the chart. Their assessment is based on the positions upheld by Antrushina, Afanasieva and Morozova, Cubeira and Heo [17-18-19].

Table 2. Frequent areas tackled in the field of vocabulary.

\begin{tabular}{ll}
\hline Field & $\begin{array}{l}\text { Areas in the field helping to delimit dimensions and } \\
\text { indicators }\end{array}$ \\
\hline \multirow{3}{*}{ Vocabulary } & $\begin{array}{l}\text { 1. Meaning } \\
\text { 2. Form } \\
\text { 3. Use } \\
\text { 4. Word formation }\end{array}$ \\
\hline
\end{tabular}

The scope of aspects embedded in the object research on this type of verbal activity tackle varies not only according to the difficulties diagnosed and contextual factors, but also to the nature of the content studied and, to an extent, of the solution offered.

The thesis entitled Multimedia for the teaching learning process of the vocabulary in Integrated English Practice I [20], covers all the areas listed. The dimensions and the indicators for each of them are as follows: meaning denotation, connotation, pertinence (adequacy to the topic), form -spelling, pronunciation and word formation, use grammatical function and collocation. In addition, the paper includes the dimension: learning strategies, a vital metacognitive content lying beneath EFL teaching and learning that is frequently neglected in vocabulary research. It comprises with three indicators - cognitive, metacognitive and socio-affective strategies.

Some of the dimensions or indicators in the previous research, such as word semantics (meaning), collocation and word formation, become the dependent variable in other papers. The study of a specific semantic zone is focused on the research A proposal of the design of an ideographic semantic dictionary of the evaluative-valuation field of English Adjectives, involving three dimensions of the meaning that make up the evaluative-valuation semantic structure of lexical semantic variants in the dictionary definitions: the modal, illocutionary and referential features. In each definition, the type of evaluation is categorized as qualifying, simple normative or analytical. Another lexicographic study that calls for particular indicators in the semantic treatment of the units covered is the paper A digital glossary of quotations on language education from Cuban outstanding personalities. Applications in English teacher education, in which the quotations are grouped according to the themes they deal with (importance of language education, its aims and characteristics, and teacher and students' role) [21, 22].

Research works devoted to English for specific purpose vocabulary are concerned with specific lexical-semantic fields, which inevitably entails considering the requirements of each academic or professional activity. The work The design of a model unit of technical language encompassing the communicative approach for second year accounting students at polytechnic schools involves two indicators of the specialized vocabulary learning: declarative knowledge (the knowledge of the content the accounting terms represent) and procedural knowledge (the skills of using them) [23].

Some content areas infrequently tackled in students' research papers are range and variety of vocabulary, treated only in certain works dealing with evaluation, intralexemic semantic relations (polysemy) and interlexemic semantic relations (homonymy, synonymy, etc.), though they often bring about difficulties for Spanish-speakers.

\subsubsection{Grammar}

Papers centered on grammar topics, their teaching and learning as a rule consider the aspects summarized in the table below. The analysis reflects Vega and Bermello's and Vega, Góngora and Zayas' viewpoints on them [24-26].

Table 3. Frequent areas tackled in the field of grammar.

\begin{tabular}{ll}
\hline Field & Areas in the field helping to delimit dimensions and indicators \\
\hline & 1. The grammatical meaning conveyed \\
2. The morphological and syntactic markers of grammatical meanings \\
3. The expression of representational and intentional meanings through grammatical forms or constructions \\
4. The contextual use of grammatical forms or constructions \\
5. The interrelation of grammatical means in the text
\end{tabular}

In fact, grammar as a level of discourse construction embraces a diverse variety of interconnected subject matters, whose study may be approached from a semantic or a formal criterion. 
Papers based on a formal (or semasiological) standpoint examine how a given grammatical form or construction helps to convey certain meanings according to the situation. This approach is followed in the paper $A$ Set of Exercises to Develop the Correct Use of "Simple" Future in Eighth Grade at Martha Abreu Secondary School, the author founds the research only on indicators, namely: adequate choice between 'going to + infinitive' and 'will + bare infinitive' depending on semantic reasons, proper use of these verb forms in the construction of declarative and interrogative sentences referring to forthcoming processes, and proper use of verbal complements expressing futurity and conveying the corresponding lexical meaning. Likewise, the paper $A$ set of activities to develop the skills of using the present perfect in second year teacher trainees is based on this approach, but the author encompasses dimensions and indicators, which are: syntactic dimension (the affirmativedeclarative, the negative-declarative, the affirmativeinterrogative and the negative-interrogative constructions), morphological dimension (the auxiliary 'have' and the past participles), and the semantic dimension (the experience, the duration, the recentness and the completion meanings). Although it may be not explicit, it is possible to establish a strong correlation between the dimensions and/or indicators of both works with the areas in table 3 , since these categories must be formulated as the specific formal, semantic and contextual features of the grammatical content dealt with in the setting explored. Otherwise, they are not suitable for the research purpose [27, 28].

When the semantic (or onomasiological) criterion is followed, the papers focus on how a grammatical meaning (a temporal, intentional or modal meaning, for instance) is expressed through different means depending on the context. For instance, coherent expression of meanings through grammatical means is an indicator of the dimension coherence in the paper $A$ system of activities to enhance speaking skills to talk about jobs and occupations in 10th graders at Capdevila's Camilo Cienfuegos Military School [29].

In general, there are three important observations about students' research on this field. It is noticeable that grammar is less frequently explored as the central focus of papers, although it is often present as a dimension or and indicator in the examination of other topics. The semasiological approach prevails in the treatment of grammatical contents; however, there is an overwhelming tendency to interconnect formal aspects with semantic and functional properties. Finally, grammar learning strategies are insufficiently considered.

\subsubsection{Discourse and Text Studies}

This field covers a great range of topics dealing with the skills for different kinds of discourse, principles of discourse construction and of textuality, functional styles of texts, types of texts according to their rhetoric function, textual relations and their means of expression, among others. This makes it difficult to define dimensions and indicators applicable to every topic, so the article just refers to some general areas and recommendations for their didactic treatment. Authors' searches in this field often use substantially different conceptual-terminological systems; the one adopted in this work develops from the approach followed by Domínguez and by Salvador et al. [30, 31].

Table 4. Frequent areas tackled in the field of discourse and text studies.

\begin{tabular}{|c|c|}
\hline Field / Topics & $\begin{array}{l}\text { Areas in the field helping to delimit dimensions } \\
\text { and indicators }\end{array}$ \\
\hline $\begin{array}{l}\text { Discourse/Text } \\
\text { construction }\end{array}$ & $\begin{array}{l}\text { 1. Semantic coherence } \\
\text { 2. Pragmatic coherence } \\
\text { 3. Cohesion (formal coherence) } \\
\text { 4. Accuracy }\end{array}$ \\
\hline $\begin{array}{l}\text { Functional style } \\
\text { and genres of texts }\end{array}$ & $\begin{array}{l}\text { 1. General function } \\
\text { 2. Linguistic features (semantic, lexical, syntactic } \\
\text { and stylistic) } \\
\text { 3. Compositional (formal) pattern }\end{array}$ \\
\hline $\begin{array}{l}\text { Types of texts } \\
\text { according to their } \\
\text { rhetoric function }\end{array}$ & $\begin{array}{l}\text { 1. General intention } \\
\text { 2. Rhetoric pattern } \\
\text { 3. Linguistic features }\end{array}$ \\
\hline
\end{tabular}

The selected research works in this field may serve as illustrations of how these general areas turn into specific categories according to the researcher's standpoints, the purpose and context of the study. They are as follows:

1. The discourse generated from racial conflicts of the Anglo-Caribbean immigrant: its presence in 'The Hanging of Angelique' [32]. The two dimensions underlying the research of this narrative text and their indicators are: formalist analysis (opening, ending, structure, plot, domain, topic, symbols, characters, setting, narrator, conflicts, style and tenor) and critical analysis of the literary discourse (situational and general contexts, expression of gender, ethnic and class relations, narrative and other rhetoric procedures, implications, linguistic structures expressing intentional or modal meanings, and punctuation).

2. A methodology based on discourse analysis to encourage the skills of developing monologues in English in language teacher education. The enquiry into the construction of this type of text is guided by the following dimensions and indicators: semantic coherence (clarity, quality and gradation of ideas), pragmatic coherence (intention, stylistic register, projected effect on interlocutors and communicative strategies), and cohesion (formal organization, connectivity of text components and accuracy in the use of linguistic means) [33]. It is worth noticing that despite the importance that the conscious use of techniques by EFL students to enhance their discourse performance and skills of text construction and interpretation, learning strategies are hardly ever tackled as research object, though some of the papers reviewed include the attention to them as part of the independent variable. A significant outcome of the previous research resides in the proposal of a guide for self-reflective communicative-functional analysis in monologue construction as a learning strategy. It is based on posing questions for projective reflection at the preparation stage, for the ongoing reflection at the "textualization" (production) stage, for the introspective reflection at the evaluation stage and for prospective 
reflection at the re-creation stage, focused on solving detected insufficiencies.

3. The representation of English-Spanish code-switching patterns in music, cinema, $T V$, and literature [34]. In the exploration of this stylistic device, the authors use as indicators the syntactic and the semantic features of codeswitching patterns as a way of representing 'Hispanic identity' through ample corpus of samples comprising different text genres: lyrics of songs, scripts of movies and TV series, and fiction. The explicit comparative perspective is regularly in the sample analyses.

In all, this field hasn't been sufficiently explored by students-researchers, particularly by undergraduates, even though most specialists and teachers agree it is essential for the communicative language teaching that emphasizes the development of discourse performance and the use of texts as the means of its realization.

\subsection{Types of Verbal Activity}

Types of discourse or verbal activity refer to the traditionally called macro-skills in EFL didactics: speaking, writing, listening and reading. The term 'type of discourse activity' is preferred here because these discourse spheres constitute modes or manners within the communicative process in which language is used depending on the role of the participant (sender or receiver) and the language code. They do not consist of a single action accomplished with a given purpose in that process, which is what a skill represents. They presuppose a wide range of particular skills, i.e. a complex system of several interrelated actions necessary to speak, to write, to listen or to read, frequently termed sub-skills, micro-skills or enabling skills in EFL didactics.

Speaking and writing, because of their productive nature, have certain similarities as to their dimensions and indicators; this is also true for listening and reading as a result of their receptive nature. In the exploration of these four types of discourse activity, the implicit comparative perspective is the prevalent, although some formal, pragmatic and sociocultural differences make advisable to exploit the explicit comparison. The positions taken for the delimitation of the areas each field comprises have evolved from the viewpoints held by Enriquez et al. [35].

The review of the papers on the types of discourse activity reveals difficulties with the pertinent delimitation of dimensions and indicators in $43.4 \%$ of them. The most common inaccuracies are the same type of those described in section 4.1. Though there is an additional one: the delimitation of a category belonging to type of verbal activity, e.g., considering 'ask for clarification' a listening skill, or to another topic, e.g. considering the listening learning strategy 'memorize chunks of language of different lengths' a skill. The assessment of each field includes content aspects that students-researchers need to cope with for a greater understanding of these spheres of discourse functioning. Likewise, the analysis includes observations on the preference of term or skill-oriented presentation of dimensions and indicators.

\subsubsection{Speaking}

In the investigation of this type of discourse activity, terms are commonly used to delimit the basic characteristics and their salient features as dimensions and/or indicators. Sometimes, the indicators are expressed as skills, which correlate with the characteristics of spoken or written utterances, since they refer to the coherent, cohesive, appropriate, accurate, fluent and interactive expression of discourse actions, carried out to accomplish certain communicative functions.

Table 5. Frequent areas tackled in the field of speaking.

\begin{tabular}{ll}
\hline Field & $\begin{array}{l}\text { Areas in the field helping to delimit dimensions and } \\
\text { indicators }\end{array}$ \\
\hline \multirow{3}{*}{ Speaking } & 1. Coherence \\
& 2. Cohesion \\
3. Fluency & 4. Accuracy \\
& 5. Appropriateness \\
6. Interactive conversational mechanisms & 7. Communication strategies \\
\hline
\end{tabular}

The following examples demonstrate how these general categories, as it occurs with fluency, are adapted to the objective, the particular context of the research, and the authors' interpretations of the terms. This is why; they must be in strict correspondence with the theoretical foundations underlying the study and the findings of the diagnosis in the initial state. Likewise, the analysis reveals how the dimensions or indicators are formulated in terms of the characteristics or the parallel skills.

In the research work entitled Communicative Activities to Enhance Free Speaking Skills to Describe Places and People in Seventh Graders at Cesar Escalante Junior High School [36], the author establishes three dimensions with the corresponding indicators: coherence (clarity and logical articulation of the ideas, logical articulation of intentions, modal attitudes and stylistic register), cohesion (correct organization of the text, correct connection of its parts and use of discourse markers) and accuracy (correct pattern of articulation and intonation, correct use of lexical items, correct use of grammatical constructions, and fluency). Fluency is viewed as a formal category expressed through the continuity of speech and the correct use of pauses.

In the work $A$ selection of videos and discussion guides to enhance the speaking skill in third year students at the School of Foreign Languages [37], the researcher only points out indicators, but their definitions explain the area of the object studied and its specific characteristics. They include coherence (the logical connection of propositions, their clarity and quality of elaboration, as well as the articulation of intentions, modal attitudes and stylistic aspects), cohesion (the organization of the text and the interconnection of its parts through cohesive devices), accuracy (phonetic, lexical and grammatical correctness) and fluency (the quality of conveying messages with ease, which encompasses turn taking, pausing, intelligibility of oral production and communicative strategies). In this case, fluency combines pragmatic and formal aspects. 
A third paper, Role plays to contribute to the development of the speaking skill in students from Immigration and Foreign Affairs Direction at Mártires de Tarará School [38], defines five dimensional areas and describes their indicators in terms of skills: fluency (making himself/herself understood and expressing clear ideas without too much hesitation), vocabulary and phonological control (articulating sounds with acceptable pronunciation, intonation and rhythm; selecting appropriate lexical means and using them correctly), grammatical accuracy (showing control over grammatical structures), activity fulfillment (accomplishing the activity on his own or with the help of others), interaction (listening to his/her partner and reacting appropriately). Here fluency integrates semantic and formal aspects.

As in previous fields, some of the areas listed in table 5 may become the object of the research, which could be illustrated with two papers focused on fluency. In the first one, A system of activities related to the communicative function 'Describing routines, habits, pastimes and hobbies' to enhance fluency in 1st year teacher trainees, fluency is conceptualized as a semantic functional category consisting in natural language use occurring when a speaker engages in meaningful interactions and maintains comprehensible and ongoing communication despite limitations in his or her communicative competence. The author only delimits indicators, including in their explanations the area and its features as follows: coherent expression of ideas (clarity and gradual progression of the ideas), contextual appropriateness (articulation of intentions and unity of stylistic register), use of communication strategies (pauses, fillers, paraphrasing). In contrast, in the second work, Developing fluency in English as a foreign language in 7th graders at Carlos de la Torre High School, fluency is considered a formal-functional category consisting in the ability to keep the flow of communication going, to use your language resources to avoid communication breakdowns. The indicators used are: appropriate pausing, a rate of speaking adequate to the learner's proficiency level, and the use of fillers and paraphrasing [39, 40].

Once more learning strategies becomes a topic to which students-researchers in this field pay less attention.

\subsubsection{Writing}

In the studies of this type of discourse activity, either term or skill-formulation are employed to define the dimensions and indicators. The correspondence of these procedures is discussed by González, Cabrer and Enríquez, and by Acosta, Rivera, Pérez and Mancini [41, 42].

Table 6. Frequent areas tackled in the field of writing

\begin{tabular}{ll}
\hline Field & Areas in the field helping to delimit dimensions and indicators \\
\hline & 1. Coherence \\
2. Cohesion \\
3riting Accuracy (lexical, grammatical, and text correctness) \\
\end{tabular}

Terms are used to outline indicators in the following works, covering several of the areas shown in table 6, namely Assessment and reinforcement of the writing skill in 1st year students at the School of Foreign Languages, in which the indicators considered to encourage and assess the development of writing skills are: unity of sentences, coherence and cohesion of the text, lexical and syntactic accuracy, word order, spelling, punctuation and text organization, and Learning strategies to develop English writing skills in 8th graders at Guido Fuentes Secondary School, in which the author proposes as indicators the writing components that each strategy emphasizes, specifically spelling and punctuation, lexical and grammatical correctness, coherence and cohesion, text organization and the use of connectors [43, 44].

The next two papers serve to illustrate the combination of term-formulation for dimensions and skill-formulation for indicators: Improving writing skills in seventh grade students at 14 de Junio Junior High School, tackling coherence (expressing logically associated ideas and intentions, and stating them clearly), cohesion (using punctuation and linking words correctly, and structuring text properly) and accuracy (spelling lexical means correctly, forming grammatical means accurately and handwriting neatly), and Mobile-assisted communicative tasks to develop English writing in eleventh grade students from Saúl Delgado High School, tackling appropriate communication (using written discourse appropriately to accomplish different communicative functions and using written means efficiently with this purpose), coherence (expressing complete, clear and interrelated ideas, developing the intention in a logical sequence and maintaining the stylistic correspondence with the situation), cohesion (organizing the information the text conveys properly and using the intrasentential and suprasentential links required) and accuracy (selecting and using vocabulary, grammatical structures, spelling and mechanics correctly) $[45,46]$.

More attention in this area require different written text types and genres, as well as acceptability, understood as the relevance and adequacy of contents for the addressee.

\subsubsection{Listening}

In the Cuban context, students' research into the receptive types of verbal activity usually resorts to the skills required in each of them. However, it is possible to distinguish different dimensional areas within both of them. Góngora and Enríquez discuss some ways in which different authors group listening and reading skills respectively [47, 48]. In tables 7 and 8 , the article offers a proposal of how to arrange the most common skills students consider in their papers in four categories, namely perception of the message, consisting in decoding or recognizing different English formal oral or written means, interpretation of ideas in context conveyed 
orally or in writing, interpretation of pragmatic meanings in oral or written interaction, dealing with interactive skills, i.e. intentions, attitudes towards the message and the interlocutor/author and style, and learning strategies.

Table 7. Frequent areas tackled in the field of listening comprehension.

\begin{tabular}{|c|c|}
\hline Field & Areas and skills in the field helping to delimit dimensions and indicators \\
\hline Listening comprehension & $\begin{array}{l}\text { Perception } \\
\text { 1. Discriminate among the distinctive sounds of English } \\
\text { 2. Recognize words in stressed and unstressed positions, pauses and intonational patterns } \\
\text { 3. Distinguish word boundaries and word order patterns } \\
\text { 4. Recognize grammatical word classes and sentences } \\
\text { Interpretation of ideas } \\
\text { 1. Predicting the contents of oral texts using prior knowledge } \\
\text { 2. Identify the gist } \\
\text { 3. Distinguish main and supporting ideas } \\
\text { 4. Understand specific and detailed information } \\
\text { 5. Infer word meaning } \\
\text { 6. Assess information from oral texts } \\
\text { Interpretation of intentions, attitudes and style } \\
\text { 1. Interpret the speakers' intentions, attitudes and style } \\
\text { 2. Understand situations, participants and their social roles } \\
\text { 3. Make inferences from nonverbal clues on speakers' attitude or mood } \\
\text { 4. Signal respect, interest, comprehension or lack thereof } \\
\text { Listening learning strategies }\end{array}$ \\
\hline
\end{tabular}

In the research paper: A set of activities to develop listening skills in seventh graders at Pedro Veliz Secondary School [49], the author establishes five indicators: recognizing words and sentence constructions, distinguishing main ideas, understanding supporting ideas, understanding detailed information, and decoding sounds, words, and phrases.

The author of the diploma paper entitled Assessment tasks to contribute to the reinforcement of the listening comprehension skill in third year students at the Faculty of Education in Foreign Languages [50], includes six indicators: predict the contents of oral texts, understand the gist of straightforward audio-material on familiar general or academic topics, understand main ideas in audio materials on familiar general or academic texts, identify specific information in audio material on familiar general or academic topics, recognize supporting details in audio materials on familiar general or academic texts, and infer speakers' intentions, opinions and attitudes in conversations on familiar everyday topics from verbal and nonverbal clues.

The thesis A methodology to develop listening learning strategies in second year students at Enrique José Varona University of Pedagogical Sciences, referred to in section 2, may help to exemplify the attention to the fourth area in table 7. Actually, the definition of the types of strategies functioning as dimensions in different papers conforms to the classification the author chooses, and the specific strategies acting as indicators within them agrees with curricular objectives and target students' needs.

It is necessary to note that research works make more emphasis on interpretation skills, and less emphasis on interactive skills. Within the first two areas, some skills deserving more attention are: understanding elliptic elements, understanding implied meanings and inferring logical connections between events and effects.

Table 8. Frequent areas tackled in the field of reading comprehension.

\begin{tabular}{|c|c|}
\hline Field & Areas and skills in the field helping to delimit dimensions and indicators \\
\hline Reading comprehension & $\begin{array}{l}\text { Perception } \\
\text { 1. Recognize the graphic code } \\
\text { 2. Identify lexis and its use in context } \\
\text { 3. Identify sentence and the relationships among its components } \\
\text { Interpretation of ideas } \\
\text { 1. Predict what the text will be about } \\
\text { 2. Get the gist of the text (skimming) } \\
\text { 3. Locate specific information (scanning) } \\
\text { 4. Identify main and supporting ideas of the text } \\
\text { 5. Get the detailed understanding of the whole text and its parts } \\
\text { 6. Interpret the text in relation to information outside the text } \\
\text { 7. Retell the information using reader's own words } \\
\text { 8. Summarize relevant points } \\
\text { 9. Assess the text information critically } \\
\text { Interpretation of intentions, attitudes and style } \\
\text { 1. Interpret the information in relation to the communicative event and situation } \\
\text { 2. Distinguish facts from opinions } \\
\text { 3. Determine the reliability of the information according reader's knowledge, views and values } \\
\text { Reading learning strategies }\end{array}$ \\
\hline
\end{tabular}




\subsubsection{Reading}

In the work $A$ system of activities to develop the reading comprehension skill in eighth graders at Pedro Ortiz Cabrera Secondary School [51], the author follows five indicators: deduce the meaning of unfamiliar words in context, identify main and secondary ideas, process the text for understanding detailed information, look for specific information in the text and interpret the message in connection with the context.

Another work for the same grade but at another school is the one entitled Enhancing Reading abilities through English lessons in 8th graders at Guido Fuentes Secondary School [52]. The researcher includes nine indicators in accordance with the pupils' difficulties diagnosed: previewing the topic of the text, recognizing words and its spelling, recognizing word classes and grammatical patterns, understanding key ideas, scanning for specific information, understanding detailed information in the text, judging the accuracy of a passage with respect to what the reader already knows, distinguishing facts from opinions, and adding information to that provided in the text and giving opinions about it.

A third work, Reading selections and activities for first year special needs teacher trainees from Fulgencio Oroz Pedagogical School [53], contains two dimensions with their indicators. Within the dimension of perception, the author proposes the indicators recognizing the graphic code, understanding lexis and its use in context, and identifying and understanding relationships within the sentence and the text; for the dimension of comprehension, skimming, scanning, identifying main and supporting ideas, getting detailed information and paraphrasing.

The analysis of the papers on this type of discourse activity reveals the ample coverage of relevant perception, interpretation and interactional skills. However, some skills within each of the areas have been relegated when they should be central, namely identifying the text structure, the relationships among its parts and their markers (perception), understanding implicit meanings using evidence to prove reader's points, interpreting the text in relation to other texts, transposing the text information to the visual code or graphic information in the text to the verbal code (interpretation of ideas), and interpreting the author's purpose, attitude and style (interpretation of pragmatic meanings). Similarly, the selection and use of reading learning strategies are not often dealt with, and when they are, belong under the independent variable.

\section{Conclusions}

The findings of the study have implication for both research and practice. With regard to the former, the results of the analysis indicate the weaknesses concerning the pertinence of the dimensions and indicators to the object explored, the content areas frequently or infrequently covered in EFL education research papers of undergraduate and Master program students dealing with levels of discourse construction and types of verbal activity, as well as the convenience of making more emphasis on the explicit comparison in their investigation. In particular, the authors of the article have pointed to topics that deserve more attention because of their impact on the teaching-learning process. Further research is needed to understand the reasons why these aspects are less considered, other than the curricular design and contextual factors adduced. This concern also extends to advisor's role in providing effective guidance concerning content coverage. With reference to practice, the study offers a Cuban approach to core conceptual bases necessary to understand the research categories treated: variables, dimensions and indicators, recommendations on the process of delimiting them, definitions of the two topics mentioned before, explanations about their areas and examples of dimensions and indicators within them treated in different papers, as well as about the comparative perspectives to their treatment. Additional work is needed to explore the acceptability of these insights and what other aspects require complementary clarification.

\section{References}

[1] Vega, J. C. \& Chala, J. M. (2020). The Research Paper Project. Unpublished.

[2] Estévez, M. (2015). Methodology to develop listening learning strategies in Integrated English Practice I and II. (Metodología para el desarrollo de estrategias de aprendizaje de comprensión auditiva en la Práctica Integral de la Lengua Inglesa I y II). Master's degree thesis. Enrique J. Varona University of Pedagogical Sciences, Havana.

[3] Walliman, N. \& Baiche, B. (2001). Your research project: a step-by-step guide for the first-time researcher. SAGE Publications: London.

[4] Medina, A., Tejeda, I., Quevedo, I., Cruz, H. \& Limonta, F. (2017). A Guide to Practicum and Research for Foreign Languages Teacher Trainees in Cuba. Félix Varela: Havana.

[5] Bermello, G. \& González, M. L. (2019). Implementing the principle of the consideration of students' mother tongue in the foreign language teaching-learning process (La aplicación del principio de la consideración de la lengua materna al proceso de enseñanza-aprendizaje de una lengua extranjera). Revista científico-metodológica Varona, No. 68 enero-abril 2019. Revista impresa ISSN: 0864-196X. Revista electrónica, ISSN: 1992-8238.

[6] Bermello, G. \& González, M. L. (2018). Comparative linguistic studies of Spanish, English and French based on the analysis of communicative functions (Estudios linguisticos comparativos del español, el inglés y el francés a partir de funciones comunicativas). Pueblo y Educación: Havana.

[7] Valledor, R. F., Ceballo, M., Blanco, M. \& Ferrás, L. M. (2009). A conception of educational research (Una concepción de la investigación educacional). In: García, G. (compiler). The diploma paper (El trabajo de diploma). Pueblo y Educación: Havana, pp. 94-106.

[8] Vega, J. C., Ronda, J. C. \& Herrera, Y. (2021). Variables, dimensions and indicators in students' research papers on EFL education. Discussion and recommendations Unpublished. 
[9] Perry, F. L. (2008). Research in applied linguistics. Becoming a Discerning Consumer. Lawrence Erlbaum Associates: Mahwah, New Jersey.

[10] Correoso, M. \& García, G. (2012). Lectures on English Phonetics \& Phonology. Félix Varela: Havana.

[11] Rodríguez, O. (2018). Teaching pronunciation communicatively in English language education. In: Enríquez, I. et al. A guide to the teaching of English in the Cuban context. Félix Varela: Havana, pp. 153-161.

[12] Fuentes, Y. (2013). Developing English pronunciation skills in the subject Phonetics and Phonology for third year students at the Faculty of Foreign Languages. (La pronunciación del inglés desde el proceso de enseñanza-aprendizaje de la Fonética y Fonología Inglesas en los estudiantes de 3er año de la Facultad de Lenguas Extranjeras). Master's degree thesis. Enrique J. Varona University of Pedagogical Sciences, Havana.

[13] Rodríguez, A. (2016). Diploma Paper. Enrique J. Varona University of Pedagogical Sciences, Havana.

[14] Suárez, R. (2017). Diploma Paper. Enrique J. Varona University of Pedagogical Sciences, Havana.

[15] Suárez, E. (2015). System of communicative exercises to develop habits of using stress patterns in English words with cognates in Spanish in secondary students from the International School of Havana. (Sistema de ejercicios comunicativos para el desarrollo de hábitos en la acentuación en la expresión oral de palabras en español con análogas en inglés en los estudiantes de secundaria de la Escuela Internacional de la Habana). Master's degree thesis. Enrique J. Varona University of Pedagogical Sciences, Havana.

[16] Valdés, A. (2014). Diploma Paper. Enrique J. Varona University of Pedagogical Sciences, Havana.

[17] Antrushina, G., Afanasieva, N. \& Morozova, N. (2004). English Lexicology. Drofta: Moscow.

[18] Curbeira, A. (2003). Readings on Semantics I (Lecturas de Semántica I). Félix Varela: Havana.

[19] Heo, L. P. (2006). Content Based Instructions: Techniques for easy teaching. English Language Teaching Forum, 41 (3), 1621.

[20] García, A. (2015). Multimedia for the teaching learning process of the vocabulary in Integrated English Practice I. (Multimedia para la enseñanza-aprendizaje del vocabulario en la Práctica Integral de la Lengua Inglesa). Master's degree thesis. Enrique J. Varona University of Pedagogical Sciences, Havana.

[21] García, G. \& Acosta, A. (2010). Diploma Paper. University of Havana, Havana.

[22] Plasencia, M. (2010). Diploma Paper. Enrique J. Varona University of Pedagogical Sciences, Havana.

[23] Miranda, E. M. (2011). Diploma Paper. Enrique J. Varona University of Pedagogical Sciences, Havana.

[24] Vega, J. C. \& Bermello, G. (2018). Communicative grammar teaching and learning in English language education. In: Enríquez, I. et al. A guide to the teaching of English in the Cuban context. Félix Varela: Havana, pp. 101-129.

[25] Bermello, G. \& Vega, J. C. (2005). Let's teach Spanish- speaking students to express their wishes in English. Approach. A Journal of English Language Teaching in Cuba. Asociación de Lingüistas de Cuba. December 2005, ISSN: 2074-0727.

[26] Vega, J. C., Góngora Perdomo, A. \& Zayas Casalí, E. S. (2020). Developing English as a foreign language teacher's research competence through the discipline English Linguistic Studies (El desarrollo de la competencia investigativa del profesor de inglés como lengua extranjera en la disciplina Estudios Lingüísticos del inglés). Revista científicometodológica Varona. No. 70, enero-junio 2020. Revista impresa ISSN: 0864-196X; revista electrónica ISSN: 19928238 .

[27] Montenegro, G. (2018). Diploma Paper. Enrique J. Varona University of Pedagogical Sciences, Havana.

[28] Hernández, A. (2018). Diploma Paper. Enrique J. Varona University of Pedagogical Sciences, Havana.

[29] Pérez, M. A. (2020). Diploma Paper. Enrique J. Varona University of Pedagogical Sciences, Havana.

[30] Domínguez, I. (2010). Communication and text (Comunicación y texto). Pueblo y Educación: Havana.

[31] Salvador, B. G., Camacho, A., Montejo, M., Álvarez, I., González, 1. M., Rodríguez, O., Hung, M. \& Arzuaga, D. (2018). Discourse analysis for foreign language teacher education. Félix Varela: Havana.

[32] Valdés, N. (2012). The discourse generated from racial conflicts of the Anglo-Caribbean immigrant: its presence in 'The Hanging of Angelique'. (El discurso generado a partir de los conflictos raciales del inmigrante anglo-caribeño: su presencia en The Hanging of Angelique). Master's degree thesis. University of Havana.

[33] Quintana, D. M. (2016). A methodology based on discourse analysis to encourage the skills of developing monologues in English in language teacher education. (Metodología basada en el análisis del discurso para el desarrollo de habilidades de construcción de textos monologados en inglés en la formación de profesores). Master's degree thesis. Enrique J. Varona University of Pedagogical Sciences, Havana.

[34] González, R. \& Mosquera, L. (2015). Diploma Paper. University of Havana, Havana.

[35] Enríquez, I., Góndora, A., Camacho, A., Bermello, G., González, M. L., Vega, J. C., Ulloa, Y., Rodríguez, O., Ronda, J. C., López, M., Garbey, E., Spicer, H., Patterson, M. C. \& Patterson, M. L. (2018). A guide to the teaching of English in the Cuban context. Félix Varela: Havana.

[36] Santiesteban, R. (2015). Diploma Paper. Enrique J. Varona University of Pedagogical Sciences, Havana.

[37] Pujadas, A. (2017). Diploma Paper. Enrique J. Varona University of Pedagogical Sciences, Havana.

[38] Valle, E. (2014). Diploma Paper. Enrique J. Varona University of Pedagogical Sciences, Havana.

[39] Trashorras, J. (2017). Diploma Paper. Enrique J. Varona University of Pedagogical Sciences, Havana.

[40] Betancourt, M. (2017). Diploma Paper. Enrique J. Varona University of Pedagogical Sciences, Havana. 
[41] González, M., Cabrer, Y. \& Enríquez, I. (2017). Teaching creative writing. Pueblo y Educación: Havana.

[42] Acosta, R., Rivera, E., Pérez, J. \& Mancini, A. (1997). Communicative language teaching. Sumptibus Publications: Australia.

[43] Fernández, A. (2018). Diploma Paper. Enrique J. Varona University of Pedagogical Sciences, Havana.

[44] Sosa Rodríguez, D. (2019). Diploma Paper. Enrique J. Varona University of Pedagogical Sciences, Havana.

[45] Chirino, A. (2015). Diploma Paper. Enrique J. Varona University of Pedagogical Sciences, Havana.

[46] González, Y. (2020). Mobile-assisted communicative tasks to develop English writing in eleventh grade students from Saúl Delgado High School. (Sistema de tareas comunicativas apoyadas por dispositivos móviles para desarrollar la expresión escrita en inglés para los estudiantes de onceno grado del Instituto Preuniversitario Urbano Saúl Delgado). Master's degree thesis. Enrique J. Varona University of Pedagogical Sciences, Havana.
[47] Góngora, A. (2018). Developing listening comprehension skills in English language education. In: Enríquez, I. et al. A guide to the teaching of English in the Cuban context. Félix Varela: Havana, pp. 1-26.

[48] Enríquez, I. (2018). On reading and reading comprehension in English language education. In: Enríquez, I. et al. A guide to the teaching of English in the Cuban context. Félix Varela: Havana, pp. 63-82.

[49] Fernández, L. L. (2018). Diploma Paper. Enrique J. Varona University of Pedagogical Sciences, Havana.

[50] Acosta, D. (2019). Diploma Paper. Enrique J. Varona University of Pedagogical Sciences, Havana.

[51] Valdés, A. (2019). Diploma Paper. Enrique J. Varona University of Pedagogical Sciences, Havana.

[52] Molinet, O. (2014). Diploma Paper. Enrique J. Varona University of Pedagogical Sciences, Havana.

[53] Sorí, Y. A. (2020). Diploma Paper. Enrique J. Varona University of Pedagogical Sciences, Havana. 